\title{
Current resistance status to temephos in Aedes aegypti from different regions of Argentina
}

\author{
G Albrieu Llinás ${ }^{1 /+}$, E Seccacini² ${ }^{2}$ CN Gardenal' ${ }^{1}$ S Licastro ${ }^{2}$ \\ ${ }^{1}$ Genética de Poblaciones y Evolución, Facultad de Ciencias Exactas, Físicas y Naturales, Universidad Nacional de Córdoba, Av. Vélez \\ Sarsfield 299, 5000 Córdoba, Argentina ${ }^{2}$ Centro de Investigaciones de Plagas e Insecticidas CITEFA-CONICET, Buenos Aires, Argentina
}

In Argentina, more than 25,000 cases of dengue were reported in the summer of 2009, even in provinces where the disease was formerly absent. We analysed the susceptibility levels to the larvicide temephos in seven populations of Aedes aegypti, the primary vector of dengue, collected during summer 2007/2008, using the susceptible Rockefeller strain as a control. Although no control failures were observed during the experiment, a majority of the lethal concentration and resistance ratio values indicate an incipient resistance. An integrative program to monitor the resistance of Ae. aegypti to insecticides is needed in the country.

Key words: Aedes aegypti - insecticide resistance - dengue

The domestic mosquito Aedes aegypti is the primary vector of dengue, the most important vector-borne arbovirosis in the world. Since vaccines against dengue are not yet available, vector monitoring and control are the only present options for the prevention of outbreaks. Currently, chemical treatment is one of the most important components in an integrated campaign (WHO 2000). In 1986, Ae. aegypti re-invaded the northern and central provinces of Argentina, reaching infestation levels even higher than those previously observed in periods prior to the termination of the control campaign in 1964 (Carbajo et al. 2001). In 1997, dengue was reintroduced in Argentina by infected persons with travel histories to Brazil, Ecuador and Venezuela (Avilés et al. 1999) and outbreaks were confirmed in northern provinces close to endemic countries (Salta, Jujuy, Misiones, Formosa and Corrientes), resulting in about 4,700 dengue cases until 2007 (Vezzani \& Carbajo 2008). In the beginning of 2009, Argentina reported more than 25,000 cases of this disease, even in provinces where the virus was formerly absent (National Ministry of Health). Extensive chemical control operations have been performed in the north of Argentina since 1998. Systematic actions began in 2002 in Clorinda (Formosa, Argentina) and in 2003 these actions continued in Iguazú (Misiones, Argentina) under the supervision of the Mundo Sano Foundation and the contribution of the Ministry of Health of Argentina, the local municipal governments, and the Research Centre of Pests and Insecticides (CIPEIN, Buenos Aires). Water

Financial support: Agencia Nacional de Promoción Científica y Tecnológica (FONCYT- PICT 14530), SECYT - Universidad Nacional de Córdoba, Chemotecnica SA

GAL is a fellow of the CONICET and a PhD student of the Doctorado en Ciencias Exactas, Físicas y Naturales - UNC, ES is a technician of the CONICET, $\mathrm{CNG}$ and SL are Career Investigators of the CONICET.

+ Corresponding author: guillermoalbrieu@yahoo.com.ar

Received 8 September 2009

Accepted 21 December 2009 containers are treated with temephos, an internationallyused organophosphorus larvicide (focal treatment), and a new cis-permethrin ultra low volume formulation (Seccacini et al. 2006) is employed as an adulticide in the event of an outbreak (spatial treatment).

Susceptibility levels to insecticides used on $A e$. aegypti must be constantly screened in different geographical areas to develop successful control strategies because artificial selection of resistant mosquito lines could result in control failures (WHO 1995). Biber et al. (2006) detected differences in resistance levels of Ae. aegypti to temephos [Abate $1 \mathrm{G}(1 \%)]$ in four natural Argentinean subpopulations previously identified by their different haplotypes. Moreover, temporal variation of larval susceptibility to temephos was analysed in Clorinda and Iguazú between 2004 and summer 2006 through summer 2007 and a weak augmentation in the resistance levels to the larvicide was observed in both cities. The resistance ratio (RR) values obtained in that study (3.099 for Clorinda and 3.057 for Iguazú) indicated an incipient resistance and no control failures were detected (Seccacini et al. 2008).

To advance understanding of the resistance of Argentinian Ae. aegypti to temephos, we determined the susceptibility levels of individuals from seven populations collected during summer 2007 through summer 2008.

Samples were collected in seven cities (Clorinda, $25^{\circ} 17^{`} \mathrm{~S} 57^{\circ} 43^{`} \mathrm{~W}$, Formosa Province; Iguazú, $25^{\circ} 36^{\circ} \mathrm{S}$ $54^{\circ} 34^{\circ} \mathrm{W}$, Misiones Province; Puerto Rico, $26^{\circ} 47^{\circ} \mathrm{S}$ $55^{\circ} 02^{`} \mathrm{~W}$, Misiones Province; Orán, $23^{\circ} 08^{`} \mathrm{~S} 64^{\circ} 19^{`} \mathrm{~W}$, Salta Province; Ledesma, 2349'S 64²7'W, Jujuy Province; Chepes, $31^{\circ} 20^{\circ} \mathrm{S} 66^{\circ} 35^{\circ} \mathrm{W}$, La Rioja Province; Córdoba, $31^{\circ} 24^{\prime} \mathrm{S} 64^{\circ} 10^{\prime} \mathrm{W}$ ) throughout the summer months from December 2007-January 2008 (Fig. 1). Larvae were taken from artificial water containers and eggs were obtained by ovitraps randomly distributed in the sampled cities, except in Puerto Iguazú, where ovitraps were located only in the proximity of the national park. In Clorinda, larvae were sampled from houses undergoing focal treatment by the Mundo Sano Foundation, which comprises the whole city. Both larvae and eggs were 
reared to adults and used to generate F1 colonies for the bioassays. The susceptible Rockefeller strain was used as a control. Colonies were established at the laboratory and thereafter maintained at $26 \pm 1^{\circ} \mathrm{C}$ with a photoperiod of 12:12 h. Mass rearing methodology and larvicidal bioassays performed on the $\mathrm{F} 1$ generation of each colony were based on the procedures previously described in Seccacini et al. (2008). One millilitre of solution was added to $224 \mathrm{~mL}$ of distilled water in a $500 \mathrm{~mL}$ plastic jar, which was shaken lightly to ensure a homogenous test solution. Next, 20 late 3rd or early 4th instar larvae were transferred to the jar following an acclimatisation over 2-3 h in $25 \mathrm{~mL}$ of distilled water. All the bioassays were conducted in a $26 \pm 1^{\circ} \mathrm{C}$ regulated chamber with a 12:12 $\mathrm{h}$ photoperiod.

Technical temephos 90\% (Ningguo Jiahua Chemistry Co, Ltd, China) was diluted in anhydrous ethanol and prepared to final concentrations between 1-32 ppb. Five different concentrations of temephos were tested: 1 ppb, 2 ppb, 4 ppb, 8 ppb and 16 ppb. Each concentration was replicated 3-5 times with 20 individuals each time; untreated cups were used for control. Mortality and survival values were recorded after the first $24 \mathrm{~h}$ exposure, and dose-mortality data from each pool were subjected to probit analysis (Litchfield \& Wilcoxon 1949). Lethal concentrations (LC) of $50 \%$ and $95 \%$ with $95 \%$ confidence limits were obtained using PoloPlus 2.0 (LeOra Software) and were expressed as ppb final concentrations. $\mathrm{RR}_{50}$ and $\mathrm{RR}_{95}$ were estimated based on $\mathrm{LC}_{50}$ and $\mathrm{LC}_{95}$ values, with the quotient between the $\mathrm{LC}$ of each population and the $\mathrm{LC}$ of the control strain as reference. The confidence intervals (CIs) for $\mathrm{LC}_{50}$ and $\mathrm{LC}_{95}$ values were also obtained (Table). To visually compare the effect of treatments on the different analysed pools, a mortality probit curve was plotted as a function of concentration on a log scale.

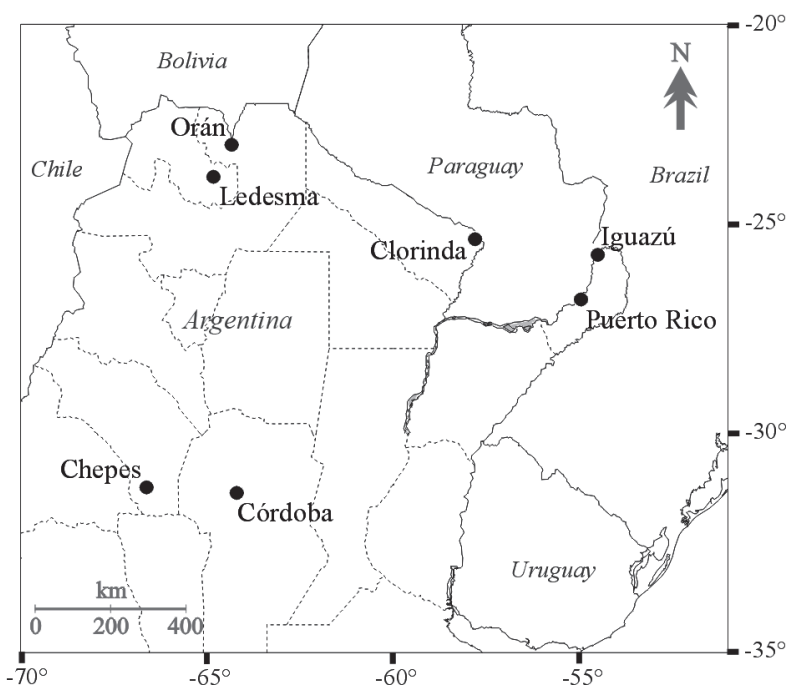

Fig. 1: partial map of Argentina showing the location of the populations analyzed in the study. Chepes: province of La Rioja; Clorinda: province of Formosa; Córdoba: province of Córdoba; Iguazú and Puerto Rico: province of Misiones; Ledesma: province of Jujuy; Orán: province of Salta.
The Rockefeller reference strain maintained its susceptibility level and its obtained LC values were consistent with historical data (Table). The log-dose probit mortality lines of most of the studied populations are shifted to the right of the one corresponding to the Rockefeller reference strain, suggesting an incipient resistance (Fig. 2). The highest RR and LC values were detected in Clorinda (Table), where houses have been consistently treated with temephos by the Mundo Sano Foundation in an uninterrupted control campaign that covered the entire urban area since 2002. These results are similar to those obtained in a previous study (Seccacini et al. 2008) and they suggest that resistant lineages are evolving in Clorinda. The RR and LC values detected in Puerto Iguazú (Table) are considerably lower than those determined in a precedent analysis in the same city during 2007 (RR $=3.057, \mathrm{LC}_{50}=9.3 \mathrm{ppb}$ ) (Seccacini et al. 2008). For this second analysis, all samples were taken in the proximities of the Iguazú National Park, where control campaigns utilising insecticides were never implemented. This may explain the higher susceptibility to the larvicide found (Table). In addition, the city of Puerto Rico without reported chemical control history showed mortality values even higher than the control strain (Table). In these cases, the segregated resistance to temephos from treated areas to untreated ones would be related to the limited active dispersal capacity of the mosquito and a low effect of passive transportation in these particular areas. According to different estimations (Edman et al. 1998), only females fly relatively long distances (50-400 $\mathrm{m}$ during the life cycle).

Furthermore, evident consequences of commercial traffic on Ae. aegypti dispersal are not expected in both the Iguazú National Park and a small city like Puerto Rico.

Ledesma showed the highest LC and RR values among the northwestern localities of Argentina (Table), which represent an initial deviation from the susceptible control strain. In a previous study (Biber et al. 2006) relatively high resistance levels were detected in the Bolivian locality of Yacuiba (Table), which is very close to the border of Argentina.

Phylogeographic studies (Rondan Dueñas et al. 2009, A Llinás, unpublished observation) based on the mtDNA $\mathrm{A}+\mathrm{T}$-rich and NADH dehydrogenase subunit 5 regions indicated that passive migration of Ae. aegypti from Brazil and Paraguay to Argentina is strongly facilitated by human commercial traffic. Although to a considerably lower degree, the introduction of haplotypes from Bolivia into Northwestern Argentina was also detected. Considering that dengue virus is emerging in provinces that used to be free of the pathogen, mosquito control campaigns based on insecticides are being developed for upcoming years in regions where sustained chemical operations have never been performed. The high levels of gene flow in Eastern and North-eastern Argentina (mainly determined by passive transportation of larvae and eggs) and the local migration detected between Bolivia and Northwest Argentina might contribute to the spreading of genes involved in organophosphate resistance into areas where the new selective pressure could increase and/or maintain the high frequency of specific genes involved in insecticide resistance. 
TABLE

Lethal concentrations ( $\mathrm{LC}_{50}$ and $\mathrm{LC}_{95}$ in ppb), resistance ratios $\left(\mathrm{RR}_{50}\right.$ and $\mathrm{RR}_{95}$ ) and slope values of Aedes aegypti larvae in seven cities from Argentina using the Rockefeller strain as control

\begin{tabular}{|c|c|c|c|c|c|}
\hline & $\begin{array}{c}\mathrm{LC}_{50} \\
(95 \% \mathrm{CI})\end{array}$ & $\mathrm{RR}_{50}$ & $\mathrm{LC}_{95}$ & $\mathrm{RR}_{95}$ & Slope \\
\hline Rockefeller & $\begin{array}{c}3.33 \\
(2.83-3.93)\end{array}$ & & $\begin{array}{c}6.14 \\
(4.95-9.34)\end{array}$ & & $\begin{array}{c}6.19 \\
( \pm 0.48)\end{array}$ \\
\hline Clorinda & $\begin{array}{c}10.17 \\
(9.19-11.34)\end{array}$ & 3.054 & $\begin{array}{c}24.043 \\
(19.96-31-52)\end{array}$ & 3.92 & $\begin{array}{c}4.4 \\
( \pm 0.46)\end{array}$ \\
\hline Iguazú & $\begin{array}{c}6.04 \\
(5.46-6.67)\end{array}$ & 1.81 & $\begin{array}{c}11.39 \\
(9.84-14.09)\end{array}$ & 1.86 & $\begin{array}{c}5.97 \\
( \pm 0.68)\end{array}$ \\
\hline Puerto Rico & $\begin{array}{c}2.94 \\
(2.27-3.79)\end{array}$ & 0.88 & $\begin{array}{c}5.83 \\
(4.36-11.45)\end{array}$ & 0.95 & $\begin{array}{c}5.54 \\
( \pm 0.52)\end{array}$ \\
\hline Orán & $\begin{array}{c}5.78 \\
(4.82-6.94)\end{array}$ & 1.73 & $\begin{array}{c}15.26 \\
(11.71-23-55)\end{array}$ & 2.49 & $\begin{array}{c}3.9 \\
( \pm 0.33)\end{array}$ \\
\hline Ledesma & $\begin{array}{c}7.28 \\
(5.71-9.48)\end{array}$ & 2.19 & $\begin{array}{c}15.84 \\
(11.54-32.59)\end{array}$ & 2.58 & $\begin{array}{c}4.87 \\
( \pm 0.46)\end{array}$ \\
\hline Chepes & $\begin{array}{c}4.09 \\
(3.28-5.15)\end{array}$ & 1.23 & $\begin{array}{c}9.69 \\
(7.18-17.22)\end{array}$ & 1.58 & $\begin{array}{c}4.4 \\
( \pm 0.34)\end{array}$ \\
\hline Córdoba & $\begin{array}{c}5.04 \\
(3.44-7.19)\end{array}$ & 1.51 & $\begin{array}{c}10.94 \\
(7.55-34.99)\end{array}$ & 1.78 & $\begin{array}{c}4.89 \\
( \pm 0.53)\end{array}$ \\
\hline
\end{tabular}

CI: confidence interval.



Fig. 2: temephos susceptibility of Aedes aegypti from seven Argentinian populations. Probit analysis of mortality as a function of concentration-log of temephos.

Although no control failures were presently observed in Argentina, the LC and RR values detected are representative of an incipient temephos resistance and if levels continue to rise the control strategies should be modified. According to the Brazilian Ministry of Health, it is recommendable to alternate temephos with other larvicides such as Bacilus thuringiensis or methoprene when RR values are higher than 3 (Montella et al. 2007); this strategy would be recommended for the Argentinean city of Clorinda, which presents an $\mathrm{RR}_{95}$ of 3.92. The insecticide resistance status of Ae. aegypti in Argentina has not been systematically verified; only sporadic reports for some areas are available. Given the present epidemiological situation and that susceptibility levels to the larvicide are beginning to decrease, it is recommended that the country start an integrative program to monitor the resistance of this dengue vector to insecticides with a strategy similar to the one carried out in Brazil since 1999 (Lima et al. 2003).

\section{ACKNOWLEDGEMENTS}

To Elizabet Estallo, Fabricio Tejerina, Andrés Visintín and Eduardo Lestani, for providing mosquito samples, to the Fundación Mundo Sano, for its assistance during the collection of larvae in Clorinda.

\section{REFERENCES}

Avilés G, Rangeon G, Vorndam V, Briones A, Baroni P, Enria D, Sabattini MS 1999. Dengue reemergence in Argentina. Emerg Infect Dis 5: 575-578.

Biber PA, Rondan Dueñas JC, Ludueña Almeida F, Gardenal CN, Almirón WR 2006. Laboratory evaluation of susceptibility of natural subpopulations of Aedes aegytpi larvae to temephos. J Am Mosq Control Assoc 22: 408-411.

Carbajo AE, Schweigmann N, Curto SI, de Garin A, Bejarán R 2001. Dengue transmission risk maps of Argentina. Trop Med Int Health 6: 170-183.

Edman JD, Scott TW, Costero A, Morrison AC, Harrington LC, Clark GG 1998. Aedes aegypti (Diptera: Culicidae) movement influenced by availability of oviposition sites. J Med Entom 35: 578-583.

Lima JB, Da-Cunha M, Da Silva RC, Galardo AK, Soares S da S, Braga IA, Ramos RP, Valle D 2003. Resistance of Aedes aegypti to organophosphates in several municipalities in the state of Rio de Janeiro and Espírito Santo, Brazil. Am J Trop Med Hyg 68: 329-333.

Litchfield JT, Wilcoxon FJ 1949. A simplified method of evaluating dose-effect experiments. $J$ Exp Therap 96: 99-100. 
Montella IR, Martins AJ, Viana-Medeiros PF, Lima JB, Braga IA, Valle D 2007. Insecticide resistance mechanisms of Brazilian Aedes aegypti populations from 2001 to 2004. Am J Trop Med Hyg 77: 467-477.

Rondan Dueñas JC, Albrieu Llinás G, Panzetta-Dutari GM, Gardenal CN 2009. Two different routes of colonization of Aedes aegypti in Argentina from neighboring countries. J Med Entom 46: $1344-1354$

Seccacini E, Lucia A, Zerba E, Licastro S, Masuh E 2008. Aedes aegypti resistance to temephos in Argentina. J Am Mosq Control Assoc 24: 608-609.

Seccacini E, Masuh H, Licastro S, Zerba E 2006. Laboratory and scaled up evaluation of $c i s$-permethrin applied as a new ultra low volume formulation against Aedes aegypti (Diptera: Culicidae). Acta Trop 97: 1-4.

Vezzani D, Carbajo AE 2008. Aedes aegypti, Aedes albopictus and dengue in Argentina: current knowledge and future directions. Mem Inst Oswaldo Cruz 103: 66-74.

WHO - World Health Organization 1995. Guidelines for dengue surveillance and mosquito control, WHO Western Pacific Education in Action Series 8, Geneva, 112 pp.

WHO - World Health Organization 2000. Dengue/dengue haemorrhagic fever. Weekly Epidemiol Rec 75: 193-200. 